\title{
REYES, NOBLES Y FRONTERA. ENTRE LA VIOLENCIA Y EL PARENTESCO EN EL ESPACIO FRONTERIZO GALAICO PORTUGUÉS (SIGLOS XII-XIII)*
}

\author{
Inés CALderón Medina \\ Universidad de las Islas Baleares \\ ORCID iD: http://orcid.org/0000-0002-1274-3691
}

* Este trabajo ha sido financiado por el Proyecto I+D «EXCELENCIA» "Poderes, espacios y escrituras en los reinos occidentales hispánicos (siglos XI-XIV)" (MINECO HAR2013-42925-P).

Copyright: (C) 2017 CSIC. Este es un artículo de acceso abierto distribuido bajo los términos de una licencia de uso y distribución Creative Commons Attribution (CC-by) España 3.0.

Cómo citar/Citation: Inés CALderón Medina, "Reyes, nobles y frontera. Entre la violencia y el parentesco en el espacio fronterizo galaico portugués (siglos XII-XIII)", Cuadernos de Estudios Gallegos, 64, núm. 130 (2017), págs. 91-117, DOI: http://dx.doi.org/10.3989/ceg.2017.130.03 


\section{REYES, NOBLES Y FRONTERA. ENTRE LA VIOLENCIA Y EL PARENTESCO EN EL ESPACIO FRONTERIZO GALAICO PORTUGUÉS (SIGLOS XII-XIII)}

\section{RESUMEN}

El nacimiento de la frontera galaico portuguesa fue un proceso complejo, pues dependió en gran medida de la capacidad de los monarcas de atraer a los nobles a su servicio y controlar el espacio. A través del análisis de las fuentes cronísticas y diplomáticas se examinará el comportamiento de la nobleza local en la definición y defensa de la frontera. Las fuentes muestran un gran protagonismo nobiliario en la guerra y en la paz en el sur de Galicia, así como las consecuencias de su fidelidad o traición. Pero además de atraer a la nobleza a su causa, los reyes intentaron solventar los conflictos fronterizos a través de los matrimonios regios, que conllevaban la entrega de los castillos y tierras en litigio como arras de las reinas de León. Ciertos nobles fueron elegidos para materializar los acuerdos matrimoniales, pues actuaron como garantes y árbitros entre los monarcas.

Palabras Clave: Toroño, Limia, Alfonso Enríquez, Frontera galaico-portuguesa, Fernando II de León, Alfonso IX de León.

\section{REIS, NOBRES E FRONTEIRA. DA VIOLENCIA AO PARENTESCO NO ESPAZO FRONTEIRIZO GALAICO-PORTUGUÉS (SÉCULOS XII-XIII)}

RESUMO

O nacemento da fronteira galaico portuguesa foi un proceso complexo, pois dependeu en gran medida da capacidade dos monarcas de atraer aos nobres ao seu servizo e controlar o espazo. A través do estudo das fontes cronísticas e diplomáticas analizarase o comportamento da nobreza local na definición e defensa da fronteira. As fontes mostran un gran protagonismo nobiliario na guerra e na paz no sur de Galicia, así como as consecuencias da súa fidelidade ou traizón. Pero ademais de atraer á nobreza á súa causa, os reis tentaron liquidar os conflitos fronteirizos a través dos matrimonios rexios, que levaban a entrega dos castelos e terras en litixio como arras das raíñas de León. Certos nobres foron elixidos para materializar os acordos matrimoniais, pois actuaron como garantes e árbitros entre os monarcas.

Palabras Clave: Toroño, Limia, Afonso Henriques, fronteira galego-portuguesa, Fernando II de León, Afonso IX de León.

\section{KINGS, NOBLES, AND FRONTIER: VIOLENCE AND KINSHIP AROUND THE GALI- CIAN-PORTUGUESE BORDER $\left(12^{\mathrm{TH}}-13^{\mathrm{TH}}\right.$ CENTURIES)}

\section{AbSTRACT}

The birth of the frontier between Galicia and Portugal was an arduous process. The control over this area relied, to a great extent, on the success of the kings of Leon and Portugal in assuring the local nobles' loyalty and service. The role played by the local nobility in the creation and military defense of this border can be analysed throughout chronicles and diplomas. These sources cast light on the nobility's key military role in southern Galicia and the political consequences derived from these nobles' loyalty or infidelity. The kings of Portugal and Leon actively seek the local nobility's support; however they also relied on royal marriages in order to solve border conflicts. In that regard, disputed landholdings and castles were given to the Portuguese monarchs as part of the Leonese queens' dowry. Some nobles were chosen as executors of these marriages agreements, so they acted as intermediaries between both kings. KEY WORDS: Toroño, Limia, Alfonso Enríquez, Galician-Portuguese border, Fernando II of Leon, Alfonso IX of Leon. 
os siglos centrales de la Edad Media hispana son un tiempo de expansión, de conquista de nuevos espacios, de organización de los espacios interiores y de creación de nuevas fronteras, como la luso-leonesa y la castellano-leonesa surgida en 1157. Es un tiempo de fortalecimiento de las monarquías feudales, en el que los reyes tienen que redefinir sus relaciones con los poderes eclesiásticos y con la nobleza para perfilar y controlar su reino ${ }^{1}$.

La ausencia de grandes accidentes geográficos en el reino de León que sirvieran como elemento definitorio de sus límites, provocó la existencia de una frontera difusa, porosa, cuyo trazado dependía en gran medida de los apoyos de los señores feudales propietarios de la tierra. El proceso de definición de fronteras dependió de la capacidad de cada monarca de atraer a la nobleza. Para ello se articularon distintos mecanismos mediante los que el rey pretendía hacerse con la fidelidad de ciertas familias. Entre las estrategias utilizadas por la monarquía destacan la concesión del gobierno de las tenencias fronterizas, la participación de estos magnates en los tratados de paz que definirían los límites del reino, etc. Asimismo el parentesco fue el arma más poderosa esgrimida por los reyes para crear sólidos lazos que les unieran a través del matrimonio o de relaciones concubinarias ${ }^{2}$.

La frontera galaico-portuguesa es además un espacio profusamente fortificado. La tenencia de estas tierras y castillos fue entregada a los miembros de la nobleza local, pero estas fortificaciones también formaron parte del patrimonio entregado en arras a las reinas de León con ánimo de terminar con los conflictos que enfrentaban a los dos monarcas vecinos.

En este trabajo se analizará cómo los reyes de León y Portugal se relacionaron entre ellos y con la nobleza en la nueva frontera galaico-portuguesa. El motivo de esta elección se debe en gran medida a las características de la nobleza asentada en este espacio en el que a partir de 1096 comenzó a dibujarse una nueva linde que,

\footnotetext{
1 Véase Inés CALDERÓn Medina, "El panorama político de la península ibérica en 1200 (ca.1150-1230)" en Esther López Ojeda (coord.), XIII Semana de estudios medievales de Nájera: 1212, un año, un reinado, un tiempo de despegue, Logroño, Instituto de Estudios Riojanos, 2013, págs. 103-138.

2 Véase Inés CALDERÓn Medina, "El concubinato regio en la definición de la frontera galaico-portuguesa (s. XII-XIII)" [en prensa].
} 
sin embargo, no fue muy sólida hasta finales del siglo XIII. Ferreira ha revelado la importancia de las relaciones familiares y feudo-vasalláticas de la nobleza transfronteriza, pues fueron utilizadas por los reyes de León y Portugal en sus políticas fronterizas ${ }^{3}$. La porosidad de la frontera y los sólidos lazos familiares facilitaron además la movilidad entre los reinos.

Se han descrito tres grandes ciclos migratorios de la nobleza durante el tiempo en el que se estaba fijando la frontera. El primero se documenta entre finales del siglo XI y el siglo XII en el que determinados miembros pertenecientes a los Traba, los Celanova/Pombeiro, Limia/Novoa, Soverosa, Toronho-Montor dejaron Galicia para dirigirse a Portugal. Entre 1157 y 1230 se viven dos periodos en los que varios nobles, como Pero Pais da Maia y Vasco Fernandes de Soverosa se enfrentaron al rey de Portugal y se dirigieron a León. En 1211 la guerra que enfrentó a Alfonso II con sus hermanas provocó que los miembros de esta nobleza transfronteriza marcharan a la corte de Alfonso IX en apoyo de Teresa de Portugal y sus hijas. Finalmente, la guerra entre Sancho II y el futuro Alfonso III motivó que este sólido grupo de parentesco pidiera el apoyo de sus parientes gallegos y leoneses para mantener a don Sancho en el trono; finalmente, tras perder la guerra se instalaron en la corte de Alfonso X ${ }^{4}$.

La nobleza transfronteriza estaba creando su propio espacio de poder basado en el parentesco, había comenzado a tejer tupidas redes parentelares que se extendían por todos los reinos peninsulares y que les garantizaban una poderosa estructura que les permitía una gran movilidad entre las cortes ${ }^{5}$.

\section{LA NOBLEZA Y LA FRONTERA GALAICO-PORTUGUESA}

El proceso de construcción de la frontera galaico-portuguesa tiene unas características que lo convierten en un ejemplo particular en la historia de la Europa Occidental, en el que el papel de la nobleza fue fundamental a lo largo de toda la segunda mitad del siglo XII y comienzos del siglo XIII' .

\footnotetext{
3 João Paulo Ferreira Martins, A Nobreza Galego-Portuguesa da Diocese de Tui (915-1381), tesis doctoral inédita, Porto, Universidad de Porto, 2016. Dirigida por José Augusto de Sottomayor Pizarro. Agradezco al autor que me haya permitido consultar su trabajo aún inédito.

4 Recientemente se ha analizado la movilidad nobiliaria entre ambas cortes. Inés CALDERón Medina y João Paulo Ferreira Martins, "Beyond the border. The aristocratic mobility between the kingdoms of Portugal and León (1157-1230)”, E-journal of Portughese History, vol. 12, núm. 1 (2014), disponible en $<$ http://www.brown.edu/Departments/Portuguese_Brazilian_Studies/ejph/html/issue23/pdf/v12n1a01.pdf $>$ [Consulta 4/03/2017].

5 Inés CALDERÓn MEdinA. "La solidaridad familiar. La participación de la nobleza leonesa en la guerra civil portuguesa (1245-1247)”, Hispania, vol. 73, núm. 245 (2013), págs. 617-645.

6 Véase José Augusto Sottomayor Pizarro, "O nascimento de Portugal. Uma perspetiva nobiliárquica (1096-1157/1300)”, Revista Portuguesa de Història, núm. 44 (2013), págs. 29-58.
} 
Las fuentes cronísticas de estos siglos narran numerosos enfrentamientos en la frontera al norte del Miño desde el nacimiento del condado Portucalense hasta finales del siglo XIII ${ }^{7}$. El momento álgido y más violento del conflicto se vivió durante el reinado de Alfonso VII, aunque posteriormente se repetirían confrontaciones bélicas en el reinado de Alfonso IX de León, durante la guerra con Alfonso II de Portugal.

Las crónicas castellanas, leonesas y lusitanas resaltan la acción nobiliaria en este espacio de frontera y la presentan como decisiva en el propio trazado de la línea divisoria entre ambos reinos. Pero además de la necesidad de la monarquía de colaborar con la nobleza, los cronistas también señalan la existencia habitual de conflictos entre reyes y nobles que provocaron alteraciones en la frontera.

Se trata de un espacio fronterizo complejo en el que además de los intereses de la nobleza local y de ambas monarquías, se encontraban implantados importantes poderes eclesiásticos como las sedes de Tuy, Orense y Braga; y de los grandes monasterios de Celanova, Melón y $\mathrm{Oia}^{8}$.

En este territorio se había ido construyendo un gran número de fortalezas que irán cambiando de señor de acuerdo a la evolución de los acontecimientos políticos vividos, y que formarán parte de las arras de las reinas leonesas. Todo ello provocó grandes dificultades en el ejercicio del poder por parte del monarca leonés, por lo que fue necesaria una constante colaboración con el poder nobiliario y eclesiástico para controlar el espacio frente a la amenaza de expansión portuguesa.

\section{EL ORIGEN DEL CONFLICTO: EL NACIMIENTO DE UNA NUEVA FRONTERA}

El proceso del nacimiento de Portugal como nueva entidad política es complejo. Provocó importantes conflictos desde que Alfonso VI dividió el antiguo reino de Galicia que había gobernado su hermano García, y entregó el gobierno

\footnotetext{
7 Véase, Carlos Manuel Reglero De la Fuente, "Visión y construcción del espacio en la Chronica Adephonsi Imperatoris", e-Spania, 15 (2013), disponible en < http://e-spania.revues.org/22367> [Consulta 5/03/2017]. María do Rosario Ferreira, "O reino de Portugal na Chronica Adephonsi Imperatoris", e-Spania, 15 (2013), disponible en <http://e-spania.revues.org/22317?lang=es $>$ [Consulta 5/03/2017].

8 Véase Paz Romero Portilla, "Un observatorio privilegiado de las relaciones de Portugal y Castilla: Tuy en la Edad Media”, en Estudos em homenagem ao Professor Doutor José Marques, vol. IV, Universidade do Porto, 2006, págs. 247-259. Ermelindo PorTELA, La región del obispado de Tuy en los siglos XII al XV: Una sociedad en la expansión y en la crisis, Santiago de Compostela, Universidad de Santiago de Compostela, 1976. Ernesto Iglesias Almeida, O antigo bispado de Tui en Portugal, Santiago de Compostela, Toxosoutos, 2007. José Marques, “A fronteira do Minho, espaço de convivência galaico-minhota, na Idade Média" en F. Ribeiro da Silva et. al. (coord.), Estudos em homenagem a Luís António de Oliveira Ramos. Porto, vol. 2, Oporto, Universidade do Porto, 2004, págs. 697-712. José MARQues, Relações entre Portugal e Castela nos finais da Idade Média, Lisboa, Fundação Calouste Gulbenkian, 1994. André Evangelista MARQuES, Da representação documental à materialidade do espaço. Território da diocese de Braga (séculos IX-XI), Porto, CITCEM, Centro de Investigação Transciplinar, Cultura, Espacio e Memória; Afrontamento, 2014.
} 
de un reestablecido condado Portucalense a su hija Teresa y a su yerno el conde Enrique. Desde ese momento "El río Miño separa Portugal de Galicia", como señala la Historia Compostelana. Esta división rompía la unidad de una amplia región que tenía una identidad común y en la que estaban asentadas familias condales: los condes Portucalenses y los de Coimbra, que habían tenido un papel fundamental en la administración del territorio desde el siglo IX y a lo largo del siglo $\mathrm{X}$, cuando llegaron a tener altas cotas de autonomía política. Sin embargo las campañas de Almanzor acabaron con el condado conimbrigense y debilitaron el portucalense ${ }^{10}$.

La llegada al trono leonés de Fernando I hizo variar la situación en el condado portucalense. El nuevo monarca se había apoyado en las familias de infanzones frente a la poderosa nobleza condal ${ }^{11}$. La fidelidad de los infanzones a Fernando I creó fuertes vínculos entre éstos y la monarquía leonesa. Los enfrentamientos entre la nobleza condal y los infanzones terminarían con la muerte del último conde portucalense en $1071^{12}$.

En su testamento Fernando I entregó el reino de Galicia delimitado al sur por el Mondego a su hijo García que, sin embargo, no pudo desplegar un proyecto político para Galicia como reino independiente debido a su cautiverio ${ }^{13}$. A su muerte su hermano Alfonso VI restituyó el condado Portucalense, en esta ocasión delimitado en el norte por el Miño y en el sur por el Mondego y se lo entregó a su hija Teresa y a su yerno Enrique de Borgoña. Esta delimitación manifestaba la ruptura entre la Galicia lucense y la Galicia Bracarense y generaba la separación de las familias asentadas en esta región ${ }^{14}$, que tuvieron que adecuarse a la nueva situación político-administrativa que rompía la unidad mantenida hasta entonces. Sin embargo, el nacimiento de esta frontera no quebraba el denso tejido de relaciones feudo-vasalláticas, familiares, patrimoniales, y políticas de las familias asentadas en este espacio que se mantuvieron durante largo tiempo ${ }^{15}$.

\footnotetext{
9 Emma Falque Rey, Historia Compostelana, Madrid, Akal, 1994, libro I, Cap. XV, pág. 98. Pedro Cardim; Luis Adão DA Fonseca y Carlos Andrés GonzÁlez PAZ, "A fronteira e a estruturação do espaço", en Luis Adão da Fonseca, (coord.), Entre Portugal e a Galiza. (secs. XI A XVII). Un olhar peninsular sobre uma região histórica, Porto, CEPESE-Fronteira do Caos Editores, 2014, págs. 225-253.

10 Acerca de la configuración de este espacio y la implantación nobiliaria véase Amélia Aguiar ANDRADE, Vilas, poder régio e fronteira: $O$ exemplo do entre Lima e Minho medieval, Lisboa, Universidade Nova de Lisboa, 1994, págs. 95-143.

11 José Mattoso, “A nobreza portuguesa no contexto peninsular”, IV Jornadas Luso-espanholas de História Medieval. As relações de fronteira no século de Alcañices. Revista da Faculdade de Letras. História, II serie, vol. XV, tomo II (1998), pág. 1022.

12 Mário de Gouveia, "Nuno Mendes (?-1071): o ultimo conde de Portucale", Revista Portuguesa de História, núm. 44 (2013), págs. 153-187.

${ }^{13}$ Ermelindo Portela, García II de Galicia, el rey y el reino (1065-1090), Burgos, La Olmeda, 2001.

14 P. CARdim; L.A. da Fonseca y C.A. GonzÁlez Paz, “A fronteira e a estruturação do espaço...”, pág. 175.

15 J. P. Martins Ferreira, A Nobreza Galego-Portuguesa..., [tesis inédita].
} 
Esta delimitación generó numerosos conflictos desde el tiempo del gobierno de Enrique de Borgoña, pero sería a su muerte cuando Teresa inició los ataques al sur de Galicia en 1116, cuando se enfrentó con su hermana en la frontera. Posteriormente, mientras mantenía una relación con el conde gallego Fernando Pérez de Traba y posiblemente con el ánimo de reconstruir la unidad del antiguo reino de Galicia dominado por la poderosa nobleza gallega, atacó de nuevo las tierras de Limia y Toroño en 1126. La Historia compostelana narra esta campaña:

\begin{abstract}
El rey don Alfonso (VII) tuvo gran discordia con su tía la reina de Portugal, llamada Teresa. Pues aquella, engreída por la altanería de la soberbia, traspasaba los límites de la justicia y no se dignaba a prestar ningún servicio por el reino que en nombre de aquél debía tener, sino que, poderosa en hombres, armas y riquezas, atacaba con ejército armado las fronteras de Galicia y las ciudades y fortalezas que estaban junto a Portugal, como Tuyy otras, y las sometía violentamente a su poder y dominio. Además hacía edificar nuevas fortificaciones en la misma tierra para inquietar y devastar la patria y para rebelarse contra el rey ${ }^{16}$.
\end{abstract}

Ante esta invasión del territorio al norte del Miño, Alfonso VII organizó una campaña en la que estuvo acompañado por casi todos los príncipes de España y solicitó la ayuda de Gelmírez que participó con sus hombres. El enfrentamiento se mantuvo durante seis semanas, tras las que Alfonso VII logró reestablecer su dominio en la zona ${ }^{17}$. La crónica no es demasiado explícita ni en los acontecimientos, ni en los lugares involucrados, ni siquiera recoge el nombre de los participantes; sin embargo informa de que don Alfonso frenó las ansias expansionistas de su tía y subraya la acción y fidelidad de Gelmírez.

\footnotetext{
${ }^{16}$ E. Falque Rey, Historia Compostelana..., Libro II, cap. LXXXV, págs. 468-469.

17 E. Falque Rey, Historia Compostelana ..., Libro II, cap. LXXXV, pág. 469. Por lo que el rey Alfonso y casi todos los príncipes de España que le apoyaron se enojaron no poco. Pero el rey vino a las regiones de Galicia y llamó a los príncipes y potestades de toda aquella tierra en expedición contra la reina. También solicitó al compostelano, que tenía mayor poder que todos los próceres de Galicia que le ayudase a reconquistar su reino y a confundir a sus enemigos. El compostelano accediendo a su ruego por amor a la justicia, reunió a todos los caballeros y peones que eran de su jurisdicción y obligó a los ciudadanos de Compostela, en parte por la fuerza, en parte con ruegos a acompañarle en aquella expedición. Asi pues, reunido un gran ejército, acompañó al rey Alfonso, que marchaba a Portugal contra la referida reina. Y alli permaneció durante seis semanas con todo su ejército devastando villas, sitiando castillos y ciudades con grandes esfuerzos y peligros. Y no volvió de alli ni permitió que su ejército volviera hasta que fue devastada casi toda la tierra y él con su consejo y prudencia restableció la concordia entre el rey y la reina.
} 
Aunque era claro que el límite lo constituía el Miño, la frontera tuvo una gran inestabilidad, sobre todo durante los reinados de Alfonso VII y Fernando II, mientras se estaba definiendo el proyecto político portugués y creando su estructura político-administrativa. En este tiempo, el apoyo de determinadas familias a los soberanos de Portugal o León provocaba un nuevo enfrentamiento y la consiguiente adhesión o pérdida de una zona sobre la que ejercer el poder. Como ha destacado Mattoso los enfrentamientos al norte del Miño hay que interpretarlos como una guerra feudal, motivada por conflictos de vasallaje, fidelidad y de soberanía y no como una guerra nacional ${ }^{18}$.

El apoyo de los Traba a Teresa tras enviudar de Enrique, tal vez, estaba encaminado a la recuperación del reino de Galicia. Fernando Pérez de Traba, que había jurado a Alfonso VII como rey de Galicia ${ }^{19}$, acumuló gran poder en la corte de Teresa entre 1121 y $1128^{20}$. Cuando sus fuerzas y las de Teresa fueron derrotadas por el infante Alfonso Enríquez, apoyado por la nobleza portucalense en San Mamede ${ }^{21}$, Fernando regresó a Galicia y volvió a ser un personaje fiel a Alfonso de León que le encargará la crianza de su hijo el infante Fernando, a quien apoyaría incondicionalmente desde ese momento.

Los hermanos Fernando, Vermudo y Rodrigo Pérez de Traba encarnan algunos de los cambios de fidelidad más llamativos de la época. Forman parte de un numeroso grupo de condes gallegos que se integran en un primer ciclo migratorio nobiliario que se trasladó de Galicia a Portucale, desde finales del siglo XI hasta mediados del siglo XII, en busca de fortuna. Entre ellos también se encuentra su cuñado el conde Gómez Núñez de Celanova/Pombeiro, que tendrá sin embargo un comportamiento muy diferente, ya que se alineó del lado del infante portugués.

\section{Los ENFRENTAMIENTOS ENTRE AlfONSO ENRÍQUEZ Y EL EMPERADOR}

Tras la victoria frente a su madre y a los Traba, Alfonso Enríquez comienza a afianzar su proyecto político y mantiene su interés por extender su hegemonía sobre las tierras situadas más allá de Miño, es decir, Limia, Toroño y Baroncelle.

\footnotetext{
18 José Mattoso, Afonso Henriques, Lisboa, Circulo de Leitores, 2006 (Reis de Portugal), pág. 98.

19 Véase Margarita Torres Sevilla, "Relaciones fronterizas entre León y Portugal en tiempos de Alfonso VII, El ejemplo de la casa de Traba", Revista da Facultade de Letras. História, vol. I, núm. 15 (1998), págs. 301-312. Acerca de la participación de los Traba en Galicia en el tiempo de Alfonso VII, véase Sonia Vital FERnÁndez, "La participación política de la nobleza gallega en el reinado de Alfonso VII (1126-1157)”, Studia Historica, Historia Medieval, núm. 29 (2011), págs. 99-120, págs. 113-116.

20 José Luis López SAngil, A nobreza altomedieval galega. A familia Froilaz-Traba, La Coruña, Toxosoutos, 2005, págs. 73-97.

${ }^{21}$ Véase José Mattoso, “A primeira tarde portuguesa”, Portugal medieval. Novas interpretações, Lisboa, Casa da Moeda, 1985, págs. 1-35.
} 
Para lograr ese fin tuvo que ganar la fidelidad de destacados nobles de la región ${ }^{22}$, pero sus ansias expansionistas entraron en contraposición con los intereses de Alfonso $\mathrm{VII}^{23}$.

Las fuentes que narran el desarrollo de los acontecimientos son escasas y no permiten conocerlos con exactitud, aunque destacan la importancia de la intervención nobiliaria; incluso presentan a ciertos magnates como los causantes de los principales conflictos y describen su traición y cambio de fidelidad. Alfonso Enríquez había conseguido que el conde de Toroño, Gomez Núñez de Celanova, y el conde de Limia, Rodrigo Pérez Veloso, hermano de Fernando Pérez de Traba, se adhiriesen a su proyecto; mientras que el conde Fernando y Rodrigo Vela defendían los intereses del emperador ${ }^{24}$.

Entretanto, parece que Alfonso VII había permitido los movimientos del infante portugués y no había interferido en los enfrentamientos con su tía Teresa, puesto que estaba planificando su matrimonio con Berenguela de Barcelona e intentando frenar los ataques y acordar la paz con su padrastro, Alfonso I de Aragón, que lo estaba atacando desde la frontera Este del reino. Sin embargo, la aparente despreocupación se terminó cuando el infante portugués cruzó el Miño y atacó la tierra de Limia, pues estaba poniendo en peligro la integridad del espacio en el que reinaba el leonés ${ }^{25}$.

Tras los primeros ataques a Limia Alfonso Enríquez pretendía controlarla mediante la construcción de ciertas fortificaciones desde las que ejercer su autoridad. Posiblemente en 1134 construyó el castillo de Celmes, situado en la tierra de Limia $^{26}$. La Chronica Adephonsi imperatoris narra cómo el infante Alfonso llevó a cabo la construcción de la fortaleza y eligió para su defensa a los nobles más audaces de su palacio. Et iterum venit in Limiam et edificanit quoddam castellum, quod dicitur Celmes, et muniuit illud nobilius militibus et audaciatoribus peditibus palatii sui, et misit in eo magna stipendia panis et carnis et uini et aque et abiit in Portugalensem terram suam ${ }^{27}$. Aunque no menciona los nombres de los elegidos, posiblemente entre ellos estaría Rodrigo Pérez Veloso y sus parientes y vasallos.

\footnotetext{
${ }^{22}$ Acerca de la actuación política de la nobleza gallega véase S. VITAL FernÁNDEz, "La participación política de la nobleza gallega...”, págs. 99-120.

${ }^{23}$ Acerca del proceso de creación de esta frontera véase la síntesis reciente P. CARDIM; L. A. DA FonSECA y C. A. GonZÁlez PAZ, “A fronteira e a estruturação...”, págs. 231 y ss.

24 A. Maya SÁnchez (ed.), “Chronica Adephonsi imperatoris”... L. I, 75, pág. 185. Iam olim multoties ipse rex Portugalensium uenerat in Galletiam et a comite Ferdinando Petri et Roderico Vele et ab aliis ducibus Galletie expulsus fuerat inde et reuersus est in terram suam sine honore.

25 A. Aguiar ANDRADE, Vilas, poder regio e frontera..., págs. 166-167.

${ }^{26}$ A pesar de los problemas de cronología del desarrollo de los acontecimientos, seguimos la establecida por J. Mattoso, Afonso Henriques..., pág. 98.

27 A. Maya SÁnchez (ed.), “Chronica Adephonsi imperatoris...”, L. I, 75, pág. 185.
} 
La construcción de una fortaleza constituía un símbolo del poder hegemónico y un elemento clave para el control del espacio, suponía una gran afrenta contra la autoridad del emperador en las tierras al norte del Miño que habían gobernado sus padres.

Las fuentes no informan de posibles negociaciones diplomáticas entre ambos primos, únicamente narran cómo Alfonso VII, guiando su ejército, se trasladó a la tierra de Limia y logró tomar el castillo. La Chronica Adephonsi Imperatoris destaca el tratamiento que el rey de León dispensó a los nobles que habían permanecido en el castillo: capturó a una gran parte de los caballeros del palacio del rey de Portugal y los puso bajo su custodia durante días ${ }^{28}$. En esta ocasión el cronista no hace referencia al nombre de los nobles que habían defendido el castillo de Celmes, aunque destaca que eran de los más poderosos de la corte del infante ${ }^{29}$; tampoco informa del lugar, ni del tiempo en el que estuvieron retenidos. $\mathrm{Ni}$ siquiera hace alusión a las posibles negociaciones ni a las contraprestaciones de su liberación.

Pero la crónica, que narra sólo el caso del castillo de Celmes, deja ver que la ocupación portuguesa en la tierra de Limia fue casi completa, pues afirma que Alfonso VII: Imperator autem, munito supradicto castello, totam Limiam ad se conuersam gauisus et reuersus est in terram Legionis ${ }^{30}$.

El autor de la Cronica Adephonsi Imperatoris acusa claramente al conde Gómez Núñez de Celanova ${ }^{31}$ y a su cuñado Rodrigo Pérez Veloso de ser los prin-

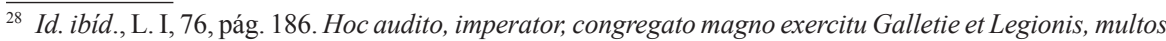
milites, festinus abiit in Limiam et obsedit supradictum castellum, quod dicitur Çelmes, et paucis diebus peractis, bellando cepit eum et cepit in eo magnam partem militum nobilium palatii regis Portugalensis misitque eos sub custodia multis diebus. Facta est autem intolerabilis tristitia in domo regis Portugalensis, quia non euerit ei sicut cogitabat.

${ }^{29}$ Es difícil identificarlos, pero si se observa la documentación de Alfonso Enríquez, se pueden observar destacadas ausencias. El último diploma regio emitido en septiembre de 1133 está confirmado por Lorenço, bene coadiutor huius regi, Gonzalo de Sousa, Gómez de Sousa, Pedro Fozaga, Fernando Captivo, el alférez, Gonzalo Vermúdez y su hermano y el mayordomo Juan Midiz, Rui Pinto de Azevedo, (ed.), Documentos Medievais Portugueses, Documentos Régios, vol. 1, t. I, Lisboa, Academia Portuguesa da História, 1961. doc. 136. La documentación de 1134 sufre una reducción importante del número de nobles en las listas de confirmantes de los diplomas emitidos en primavera, que apenas están confirmados por Egas Moniz, armiger regis, Ermigio Moniz, maiordomo, Gueda Menéndez, Nuno Suárez, Menendo Acha, Lourenço Vegas; lo que puede llevar a entender que gran parte de la curia, que había confirmado el diploma de septiembre de 1133, podría estar entre los cautivados en Celmes. $I d$, ibd, docs. 134-139. Se conserva un diploma emitido en noviembre en Coimbra confirmado por: Fernando Perez Captivo, dapnifer; Mendo Muñoz, Gonzalo Rodríguez, Gonzalo de Sousa, Juan Ranna, Nuno Suarez, el viejo, Menendo de Bragança, signifer, pero es una falsificación. Id. ibid., doc. 141, lo que no permite verificar su cautiverio ni su regreso a la corte. A. Maya SÁnchez (ed.), “Chronica Adephonsi imperatoris...”, L. I, 77, pág. 186.

30 A. Maya SÁnchez (ed.), “Chronica Adephonsi imperatoris...”, L. I, 77, pág. 186.

31 Sonia Vital ha analizado la rebelión del conde Gómez, sin embargo no destaca su filiación, lo que resulta imprescindible para comprender su participación y sus intereses a ambos lados de la frontera, véase S. Vital Fernández, "La participación política de la nobleza gallega...”, pág. 115. Su padre el conde
} 
cipales causantes de este conflicto, pues se habían adherido al bando del infante portugués $^{32}$. A pesar de los problemas que genera la fuente acerca del orden y cronología de los acontecimientos narrados, el relato es muy elocuente en cuanto a la transcendencia de la actuación nobiliaria en este conflicto fronterizo.

Ciertamente el conde Gomes Nuñez de Celanova/ Pombeiro era uno de los magnates más poderosos de la frontera, su familia estaba asentada en la tierra de Toroño desde el tiempo de Fernando I, por lo que su actuación fue fundamental en el nacimiento de Portugal. Era hijo del conde Nuño Vázquez de Celanova y Sancha Gomes de Sousa ${ }^{33}$. Había comenzado su carrera política en 1110-111 como gobernador del castillo de São Cristovão, en 1112 fue mayordomo del conde Enrique, tras la muerte del conde recibió la tenencia de Toroño. Era cuñado del conde Fernando Pérez de Traba, pues estaba casado con su hermana Elvira Pérez de Traba. En 1117- 1118 estaba al lado de Alfonso VII al que había jurado como rey ${ }^{34}$; sin embargo cuando su cuñado se trasladó a la corte de la condesa Teresa, Gómez Núñez le siguió y confirmó varios diplomas junto a él en tierras lusas ${ }^{35}$. Parece que hasta San Mamede estuvo al lado de Teresa y los Traba, aunque poco después fue atraído por el Infante Alfonso de Portugal. Sin embargo, en este tiempo tuvo una gran movilidad entre las cortes ya que se le documenta en la corte leonesa en 1125 y $1133^{36}$. Parece que en ese momento rompe su fidelidad a Alfonso VII y en 1134 se pone al servicio de Alfonso Enriquez, teniendo un papel relevante en la campaña de $\operatorname{Celmes}^{37}$. Además en ese tiempo su hija Châmoa inició una relación concubinaria con el infante portugués, que estrechaba la alianza entre ambos ${ }^{38}$.

\footnotetext{
Nuño era primo del último conde de Portugal asesinado en 1071 y estaba emparentado con los Sousa tras casar con Sancha Gomes de Sousa. Sus hijos diseñaron una potente política matrimonial al casar Gómez Núñez con Elvira Pérez de Traba y Sancho Núñez con una hermana de Alfonso Enríquez. Además reforzó la alianza con Alfonso Enríquez mediante una relación concubinaria entre el infante y su hija Châmoa Gomes. Casó a su otra hija con Fernando Iohannes de Montor-Toroño que tuvo un papel fundamental en la defensa de la frontera, como se destaca en las siguientes páginas. José MATToso, Identificação de um país. Oposição, vol. II, Lisboa, Estampa, 1995, pág. 127. José Augusto Sottomayor PizArRo, As linhagens medievais portuguesas: genealogías e estratégias, (1279-1325), vol. I, Porto, Centro de Estudos de Genealogia, Heráldica e História da Família, Universidade Moderna, 1999, pág. 510.

32 A. Maya SÁnchez (ed.), “Chronica Adephonsi imperatoris...”, L. I, 77, pág. 186. Hoc autem factum est, antequam uocaretur imperator, sed postquam imperator est uocatus, sicut prediximus, comes Gomez Nunii et comes Rodericus, qui Villosus uocatus est, rebelles facti sunt in Galletia dederuntque honores et castella regi Portugalensi, qui muniuit ea et reuersus est in terram suam.

${ }_{33}$ Sobre el conde Gómez Núñez véase J. Matтoso, Identificação de um país. Oposição..., pág. 127.

${ }^{34}$ Manuel Fernández Rodríguez, Toronium: aproximación a la historia de una tierra medieval, Santiago de Compostela, CSIC, 2004 (Anejos de Cuadernos de Estudios Gallegos, 31), págs. 76-79.

35 Íd. ibid., pág. 80.

${ }^{36}$ Estuvo presente en su proclamación en Zamora. Íd. ibid., págs. 82-83.

37 S. Vital FernándeZ, "La participación política de la nobleza gallega...", pág. 109.

38 Acerca del uso del concubinato en la definición de la frontera, véase I. CALDERÓn MEdina, "El concubinato regio en la definición...", [en prensa].
} 
Los enfrentamientos en la Limia y Toroño continuaron a lo largo de la década de los años treinta del siglo XII. Posiblemente en $1136^{39}$, mientras el rey de León estaba sofocando la revuelta del rey de Navarra, Alfonso Enríquez volvió a cruzar el Miño e invadió la ciudad de Tuy y otros castillos. En ese momento, el conde Gómez Núñez, que poseía la tenencia de los castillos y la tierra de Toroño, y el conde Rodrigo Pérez el Veloso que tenía los castillos de la tierra de Limia y un dominio de manos del emperador, engañaron a su señor y entregaron sus dominios al rey de Portugal. Además de ello, ambos prepararon la guerra contra Alfonso VII. Las consecuencias de esta traición les persiguieron todos los días de su vida, según el cronista ${ }^{40}$.

El autor de la Chronica Adephonsi Imperatoris achaca la responsabilidad de la pérdida de este espacio, que pasó a formar parte del dominio del rey de Portugal, a la traición del conde Gómez Núñez y de Rodrigo Pérez Veloso; mientras alaba la acción de los fieles defensores de los derechos del emperador sobre esta tierra. En este momento se trataba del conde Fernando Pérez de Traba y Rodrigo Vela ${ }^{41}$, que se habían enfrentado a los traidores en Cernesa, en tierra de Limia. Et rursus rex Portugalensis, congregato agmine suo, uenit in Limiam. Hoc audito, comes Fernandus Petri et comes Rodericus Vele et ceteres duces imperatoris Galletie omnes pariter conuocati militia sua exierunt aduersus regem et obuiauerunt ei in loco, qui dicitur Cernesa, et paratis aciebus ceperunt preliari et, peccatis exigentibus, terga uerterunt comites et uicti sunt ${ }^{42}$. Este enfrentamiento se saldó con el efímero cautiverio de Rodrigo Vélaz, conde de Sarria, a manos de los hombres de Alfonso Enríquez ${ }^{43}$.

Asimismo, y en contraposición a la actitud traidora de los condes Gomez Núñez y Rodrigo Pérez, el autor de la crónica exalta la fidelidad y las consecuencias de ésta en la figura del dux Fernando Iohannes de Montor-Toroño, tenente del

\footnotetext{
39 Seguimos la cronología de los acontecimientos establecida por J. Matтoso, Afonso Henriques..., pág. 100. En mayo de 1136 el infante portugués dona la villa de Paredes en Viana do Castelo al monasterio gallego de Toxosoutos, tal y como la había tenido en tiempo de su abuelo y su madre; lo que indica el interés del infante por tener buenas relaciones con dicho cenobio, Rui P. Azevedo (ed.), Documentos Medievais Portugueses, Documentos Régios, Documentos dos condes portugueses e de D. Alfonso Enriques. A.D. 1095-1185, vol. 1, Tomo I, Lisboa, Academia Portuguesa da História, 1958-1962, doc. 154.

40 A. Maya SÁnchez (ed.), "Chronica Adephonsi imperatoris...", L. I, 74, pág. 185. Comes uero Gomez Nunii, qui tenebat castella multa et terram quam dicunt Torogno, et comes Rodericus Petri Villosus, qui tenebat castella in Limia et ad imperatore honorem, uterque mentiti sunt domino suo imperatori dederuntque castella et honores regis Portugalensi; et hoc non sufficit eis, sed insuper parauerunt bellum ad damnationem sui, hec omnia quod impediuit potius comites omnibus diebus uite sue.

${ }^{41}$ Eran consuegros ya que la hija que Fernando Pérez de Traba había tenido con Teresa de Portugal, doña Sancha Fernández, había casado con el hijo de Rodrigo Vélaz, don Álvaro Rodríguez de Sarria.

${ }^{42}$ A. Maya SÁnchez (ed.), “Chronica Adephonsi imperatoris...”, L. I, 78, pág. 186.

43 Íd. ibid., L. I, 78, pág. 186. Comes uero Rodericus Vele a quibusdam militibus regis captus est in bello, sed protinus a duobus suis armigeris, facto magno ingenio, liberatus et fugit cum eis.
} 
castillo de Allariz, quien, junto a sus hijos y otros parientes resistió a los ataques portugueses $^{44}$, lo que le llevó a alcanzar alta gloria por la defensa del reino y por su servicio fiel a Alfonso VII ${ }^{45}$. Además incide en su constante labor de defensa de la frontera que llevó a cabo en todo este tiempo ${ }^{46}$. Relata el valor y destreza de los hombres de don Fernando, que lograron herir a Alfonso Enríquez y el propio Fernando apresó a algunos de los consejeros del rey, a los que liberó tras quitarles sus riquezas ${ }^{47}$.

Este valiente caballero de Limia es Fernando Iohannes de Montor-Toroño, era yerno del conde Gómez Núñez, junto a él desarrolló una parte de su carrera política. Durante algún tiempo había gobernado Toroño junto a él y en 1125 don Fernando lo acompañó a la corte de Teresa de Portugal, pues juntos confirman dos donaciones que ésta hace a la catedral de Tuy ${ }^{48}$. Tras la muerte de Urraca y de nuevo junto a su suegro, juró fidelidad a Alfonso VII; sin embargo los intereses comunes se quebraron con el cambio de fidelidad del conde Gómez. Además estaba emparentado con Rodrigo Pérez Veloso, pues era tío de su esposa.

Mientras que ambos magnates optaron por apoyar al infante portugués, Fernando Iohannes continuó siendo fiel al emperador, al que sirvió en sus campañas al sur. Su fidelidad le granjeó además del dominio de Limia, una cierta relevancia en la corte imperial y a sus hijos posteriormente en la de su hijo, Fernando II. Años después, sus hijos Pelayo Curvo y Varela continuarían al frente de la tenencia de Toroño ${ }^{49}$.

Los ataques reiterados del portugués sobre Limia preocupaban sobremanera al emperador que se trasladó hasta la ciudad de Tuy en la que entró sin combate. Aunque las fuentes cronísticas no narran el encuentro entre los primos, se conserva el llamado tratado de Tuy, fechado el 4 de julio de 1137, por el que establecen las

\footnotetext{
44 Sobre los hijos de Fernando Iohannes véase José Antonio Souto CABO, "Fernando Pais de Tamalhancos. Trovador e Cavaleiro", Revista de Literatura medieval, Universidad de Alcalá, núm. 24 (2012), págs. 231-267.

45 A. Maya SÁnchez (ed.), "Chronica Adephonsi imperatoris...", L. I, 75, pág. 185. In diebus illis erat in Limiam quidam dux domine Fredinandus Iohannis, strenuus miles imperatoris et amicus fidelis, tenebatque castellum quod dicitur Alleris et alia plurima, ideoque ipse et filii et fratres eius et amici uiriliter parauerunt bellum contra regem Portugalensium; non tamen a regis bello fatigati suum honorem perdiderunt, ceterum laudem maximam consequuti sunt.

46 Íd. ibid., L. I, 81, pág. 187. Fernandus Iohannis, princeps Limie, cum ceteris fidelibus imperatoris quotidie agebat bellum contra regem, cum quo bello congressus uiriliter pugnauit

${ }^{47}$ Íd. ibid., L. I, 81, pág. 187. Nam et ipse rex uulneratus est lancea, quam unus de peditibus Fredinandi Iohannis audacter adegit, laborauitque multis diebus et a medicis curatus. Hoc autem bello Fredinandus predictus cepit aliquod ex principibus regis et expoliatos magnis diuitiis dimisit.

48 R. Pinto de Azevedo (ed.), Documentos Medievais Portugueses, Documentos Régios..., docs. 70 y 71.

49 Inés CALderón Medina, Cum magnatibus regni mei. La nobleza leonesa y el poder regio durante los reinados de Fernando II y Alfonso IX de León (1157-1230), 74, Madrid, CSIC, 2011 (Col. Biblioteca de Historia), págs. 319-320. En las páginas siguientes se analizará la carrera política de los hijos de Fernando Iohannes.
} 
líneas básicas de su relación ${ }^{50}$. El infante de Portugal se comprometía a no atacar la tierra del emperador, aunque en el texto no se hace ninguna referencia a límites espaciales, posiblemente porque estaban bien establecidos en el Miño. Además el portugués acuerda ayudarle frente a cualquier enemigo, mientras que Alfonso VII se garantiza la fidelidad de su primo y, sobre todo, pacifica esta frontera. Es factible que a estas negociaciones asistieran los nobles más destacados de cada corte $^{51}$, sin embargo el diploma sólo informa de la presencia de los obispos de Braga, Segovia, Oporto, Tuy y Orense; es decir las diócesis con intereses en la zona o próximas al conflicto, además del obispo castellano de Segovia ${ }^{52}$.

Esta paz que pretendía ser duradera, pues el infante Alfonso indicaba que debía ser asumida también por los hijos del emperador, fue efímera puesto que Alfonso Enríquez volvió a invadir, en los primeros meses de 1141, las tierras de Limia y Toroño, haciéndose con varios castillos. Cuando el emperador tuvo constancia de este ataque, se dirigió hacia la frontera gallega con su ejército que se encontró con la hueste portuguesa en el lugar de Valdevez ${ }^{53}$. Las fuentes muestran versiones diferentes sobre lo acontecido en Valdevez, además señalan distintos agentes como los artífices de la paz.

Ambas fuentes, la Chronica Adephonsi Imperatoris y los Annales de Alfonso Enríquez mencionan a distintos personajes participantes en estos acontecimientos: mientras que la Chronica Adephonsi Imperatoris incide en la participación y cautiverio del conde Ramiro (Froilaz) ${ }^{54}$, los Annales D. Adeponsi portugalensis rex, describen el desarrollo de un torneo que ganaron los nobles portugueses ${ }^{55} \mathrm{y}$

\footnotetext{
50 José Antonio Fernández FlóRez, Colección diplomática del monasterio de Sahagún (857-1300), León, 1991, doc. 1263 (Col. Fuentes y Estudios de Historia Leonesa, vol. 38).

51 Un diploma emitido el mismo mes de julio por Alfonso Enríquez está confirmado por: Martin Iohannes, signifer, Pedro Iohannes su mayordomo, Lorenzo Suárez, Juan Fernández, Fernando Fernández, Gómez Suárez, Gil Vázquez, Rodrigo Menéndez, Ponce Alfonso, Lope Alfonso; y los obispos del reino. R. Pinto de azevedo, (ed.), Documentos Medievais Portugueses, Documentos Régios..., vol. I, doc. 159, lo que hace pensar que posiblemente también estarían presentes o, al menos, al tanto, de las negociaciones de Tuy.

52 José Antonio Fernández FlóRez, Colección diplomática del monasterio de Sahagún (857-1300), León, 1991, doc. 1263 (Col. Fuentes y Estudios de Historia Leonesa, vol. 38), doc. 1263.

53 A. Maya SÁnchez (ed.), “Chronica Adephonsi imperatoris...”, L. I, 82, pág. 188. Ipse autem imperator, congregata magna militia terre Legionis, abiit in Portugale et cepit munita castella et destructa est terra magna atque predata. Rex autem Portugalensis, congregato agmine suo, exiit in prelium contra paucos, qui stulte de exercitu imperatoris exierant. A. MAYA SÁNCHEZ (ed.), "Chronica Adephonsi imperatoris...", L. I, 83, pág. 188. Deinde imperator castra metatus est a facie Castelli, quod dicitur Penna de Regina, in loco, qui uocatur Portella de Vice. Rex autem Portugalensis fixit tentoria sua a facie castrorum imperatoris in loco altiori et aspero uallisque erat inter illos. Sed multi duces et milites regis descendentes de castris commiserunt bellum inter se et multi corruentes de equis in terram capti sunt ex utraque parte.

54 A. MAYA SÁnchez (ed.), “Chronica Adephonsi imperatoris...”, L. I, 82, pág. 188. Qui postquam obuiauit comiti Radimiro expugnanti terram suam, uterque commiserunt bellum. Et uictus est comes Radimirus et captus a rege.

${ }_{55}$ Monica Blöcker-Walter, Alfons I von Portugal. Studien zu Geschichte und Sage des Begrunders der portugiesichen Unbhangigkeiten, Zurich, Fretz und Wasmuth Verlag, 1966 (incluye en anexos) Annales
} 
tras el que cautivaron a Fernando Hurtado, el hijo de la reina Urraca, además del conde Ponce de Cabrera, Vermudo Pérez (de Traba), Varela, el hijo de Fernando Iohannes, y Rodrigo Fernández el padre de Fernando Rodríguez y Martín Kabra, consobrino del conde Ponce de Cabrera; sin embargo no menciona al conde Ramiro ${ }^{56}$.

Ambos autores señalan el protagonismo de los nobles consejeros de los monarcas en la solución pacífica del conflicto, lo que suponía la definición y estabilización de la frontera norte. La Chronica Adephonsi Imperatoris destaca como una iniciativa de la nobleza portuguesa la devolución de los castillos que el monarca había arrebatado al emperador ${ }^{57}$. Los magnates - maiores natu-portugueses, que habían perdido un gran número de hombres en los ataques sarracenos a Leiría, expresaron al rey la conveniencia de pedir al emperador la paz, proponiéndole la devolución de los castillos, ante lo que éste mostró su acuerdo. Entonces, los consejeros de Alfonso Enríquez se entrevistaron con Alfonso VII, al que agradaron sus propuestas. De inmediato, los mensajeros lusitanos recibieron la garantía de los próceres leoneses de que no se rompería la paz.

Posteriormente, los consejeros imperiales se dirigieron al campamento del portugués donde, igualmente, sus nobles dieron garantía a los leoneses de que la paz se mantendría. Al día siguiente, los condes del emperador y los nobles lusitanos establecieron los términos de la paz que conllevaba la devolución de los castillos que el portugués le había arrebatado en Galicia, así como Alfonso

D. Adeponsi portugalensis rex, pág. 154. D. Alfonsi, coadunato omni suo exercitu de Castella et de Gallecia, voluit intrare regum Portugallie, et uenerunt usque ad locum, qui dicitur Valdevez; sed rex Portugal D. Alfonsus ocurrit ei cum exercitu suo et obsedit iter,per quo dille venire volebat, fixitque tentoria sua, isti ex hac parte et illi ex altera parte. Cumque veniret aliquis ex parte imperatoris ad Iudendum, quod populares dicunt Bufurdium.

${ }_{56}$ Íd. Ibíd., pág. 154. Qui in exercitu comprehenderunt Fernandum Furtado, fratrem imperatoris et consulem Pontium de Cabreira et Veremundum Petri et Varela, filium de Fernando Iohannis, germanum de Pelagio Curvo et Rodericum Fernandi, patrem de Fernando Roderici et Martinum Kabra, consobrinum consulis D. Pontii et alios multos, qui cum eis venerunt.

57 A. MAYA SÁNCHEZ (ed.), "Chronica Adephonsi imperatoris...”, L. I, 82, pág. 188. Videntes autem hoc bellum maiores natu Portugalensium dixerunt regi suo: Domine rex, non est nobis bonum aut utile habere bellum cum imperatore neque semper poterimus sustinere multitudinem eius tam magnam et tam fortem. Non erit crastina nobis sicut hodie. Si pax inter nos esset, omnes fratres nostri, qui perierunt a manibus sarracenorum in castello de Erena, non perissent. Sed prouide ne forte iterum ueniat Maobite et Agareni in ciuitatibus et in castellis nostris, que sunt trans flumen Dorii, et faciant peiora quam fecerunt. Iube ergo ut eant aliqui de nobis ad rogandum imperatorem, ut faciat nobiscum pacem. Et demus ei omnia sua castella, que habemus, et ille restituat nobis illa, que sui milites ceperunt de nostris. Melius est enim nobis habere pacem quam bellum. A. MAYA SÁNCHEZ (ed.), “Chronica Adephonsi imperatoris...”, L. I, 85, pág. 189. Rex autem consilio audito principum suorum, placuit ei et misit nuntios de maioribus domus sue ad imperatorem, qui ei dicerent supradicta uerba de pace regum. Quibus auditis, imperator placuerunt ei. Post hec nuntii regis receperunt fidem a principibus ut haberent pacem inter se, usquequo supradicta pax aut compleretur aut, quod Deus non permitta, negaretur. Tunc denique principes imperatoris abierunt in castra regis et similiter acceperunt fidem a principibus regis, sicut illis dederant. 
VII devolvió aquellos que había tomado de Alfonso Enríquez. Además se pactó la liberación de los cautivos de ambos reinos ${ }^{58}$.

La narración de los Annales no indica las consecuencias de la negociación de Valdevez en la que participaron el obispo de Braga y algunos hombres buenos, aunque no los nombra; poco después en la tienda del portugués los monarcas sellaron la paz y festejaron su acuerdo ${ }^{59}$.

El autor de la Chronica Adephonsi Imperatoris incide en acusar a los condes gallegos Rodrigo y Gómez Núñez como los provocadores de los enfrentamientos fronterizos entre los monarcas, y narra las consecuencias que tuvo para ambos magnates: El rey apartó de su servicio al conde Rodrigo y al conde Gómez Núñez porque habían provocado la discordia ${ }^{60}$. Además narra las distintas soluciones a este conflicto que el emperador adoptó con ambos magnates. El conde Gómez, según la crónica, abandonó la península y se refugió en el monasterio de Cluny ${ }^{61}$, sin embargo los nobiliarios portugueses afirman que fue enterrado en el monasterio de Pombeiro, lo que hace suponer que pudo haberse trasladado más allá de los Pirineos durante algún tiempo, aunque regresó a Portugal y eligió como lugar de sepultura el cenobio relacionado con su familia. El enfrentamiento entre el emperador y el conde Rodrigo se solucionó con el perdón por parte del monarca que lo restituyó a su servicio ${ }^{62}$.

Tras estos conflictos bélicos en la frontera galaico-portuguesa y el reconocimiento de la autoridad de Alfonso Enríquez en Zamora en 1143, la tensión se relajó en este espacio, durante algunos años, aunque las intenciones expansivas del portugués no habían desaparecido.

\footnotetext{
${ }_{58}$ Íd. íbid., L. I, 86, pág. 189. Altera autem die comites imperatoris coniuncti sunt cum principibus regis et fecerunt pacem inter imperatorem et regem, non absolute sempieternam, sed per aliquot annos, et iurauerunt eam ut iterum, dum pax esset, firmius pacificarentur, sicut placuerat utrisque. Et redacta sunt vicariis imperatoris omnia castella, que Portugalensis rex acceperat in Galletia, et similiter regni sua, que milites imperatoris acceperant ab eo bello. Tunc solutus est comes Radimirus et omnes milites, quicumque capti ex utraque parte fuerant, soluti sunt.

${ }_{59}$ M. Blöcker-W Alter, Alfons I..., pág. 154. Misit pro archiepiscopo Bracharensi D. Ioanne et aliis bonis hominibus, et rogaverunt eos, ut venirent ad regem Portugalis, ut pacem bonam, et firmarent ea, quae pacis sunt in perpetuum. It factum est. Conuenerunt namque in suo tentorio ab eo pariter imperator et rex Portugallis et osculati sunt inuicem et comederunt et biberunt in unum et locuti sunt soli secretius, et sic remeauit unusquisque in propia in pace.

${ }^{60}$ A. Maya sánchez (ed.), “Chronica Adephonsi imperatoris...”, L. I, 87, pág. 189. Facta est pax inter illos per multos annos, que, quia bona Christianis, utilis uisa est. Et rex abiecit a se comitem Rodericum et comitem Gomez Nunii pro eo quod ipsi immiserant discordiam inter imperatorem et regem.

${ }^{61}$ Íd. ibíd., L. I, 87, pág. 189-190. Comes Gomez Nunii, ut cognouit se ese reum, uerecundatus est et transiens fugiendo montes Pirineos, uellet nollet, quia nusquam erat ei locus ad habitandum, fecit se monachum in monasterio Cluniacensi. Imperator uero misericordia motus super comitem Rodericum iussit eum comedere panem coram se in palatio suo et dare stipendia auri et argenti sicut uni ex principibus suis, qui assistebant coram se.

62 S. Vital FernÁndez, "La participación política de la nobleza gallega...”, págs. 110-113, 117. M. TorRes SEvilla, "Relaciones fronterizas entre León y Portugal...” págs. 310-312.
} 


\section{Alfonso Enríquez y Fernando II de León}

A partir de entonces los reyes de León confiarían la tenencia de Limia y Toroño a quienes habían demostrado su fidelidad. Tras la desaparición de Fernando Iohannes de Montor-Toroño, fue su hijo Pelayo Curvo quien tuvo la tenencia de Toroño entre 1149 y 1160. Don Pelayo aparece por primera vez en la documentación regia en 1135 cuando confirma numerosos diplomas regios ${ }^{63}$. En junio de 1137 estaba en Tuy en la corte del emperador, lo que hace suponer que acompañara a su padre Fernando Iohannes en la defensa de Limia y que participara en la campaña llevada a cabo por don Alfonso en este tiempo, como señalaba la Chronica Adephonsi Imperatoris ${ }^{64}$. En 1149 confirma como domus in terra Tudensi $y$ potestas et dominus in terra Tudensi ${ }^{65}$. En 1152 confirma varios diplomas como tenente in ipsam terram y como Pelagius Curuus, Galletie, lo que da una idea del aumento de su poder que mantendrá hasta la muerte de Alfonso VII ${ }^{66}$.

El nuevo monarca, Fernando II, para garantizar su fidelidad y compensarlo por las propiedades perdidas en Portugal, le donó en 1158 pro bono et fidele servicio quod mihi a puerita fecisti et pro possessionibus et pro hereditatibus vestris quas in servicio meo perdidistis quas scilicet hereditates vobis rex Portugalis inimicus destruxit $t^{67}$. Todas estas heredades de Causo, Belsar, Mougales, Manuffi, Fornelos de Crescende, Nogueira y Canadello, Masende, Canedello de Lourima se encuentran en la frontera, en las tierras de Limia y Toroño; de este modo el monarca leonés aumentaba la implantación y el poder de Pelayo en la región ${ }^{68}$.

La documentación pone de manifiesto una especial afectividad entre el nuevo monarca hacia Pelayo Curvo al que denomina charissimo. Además en su corte logrará otros importantes cargos como la tenencia de San Paio de Luto en $1160^{69}$

\footnotetext{
63 Manuel Recuero Astray, Marta González Vázquez y Paz Romero Portilla, Documentos Medievales del Reino de Galicia: Alfonso VII (1116-1157), La Coruña, Xunta de Galicia, 1998, págs. 61, 66, 67.

${ }^{64}$ Íd. ibíd. Está presente en la corte en 1137,1138 y 1140, págs. 67, 69, 71, 73, 79, 86, 87 y 93 . En 1142 confirma varios diplomas. Íd. ibíd págs. 96, 97. En 1144 continuaba en entorno imperial, Íd. ibíd., pág. 103, y acompañado de sus hijos, Íd. ibíd., págs. 106, 107. Entre 1145 y 1149 confirma varios diplomas regios, Íd. ibid., págs. 111, 117, 121 y 126.

${ }_{65}$ M. Recuero Astray; M. González Vázquez y P. Romero Portilla, Documentos Medievales del Reino de Galicia, Alfonso VII..., págs. 127, 130.

${ }^{66}$ Id., ibid., págs. 155, 156, 159, 160, 170, 177, 179, 187, 189, 191.

${ }^{67}$ Manuel Recuero Astray (dir.); Paz Romero Portilla y Ángeles Rodríguez Prieto, Documentos Medievales del Reino de Galicia, Fernando II (1155-1188), La Coruña, Xunta de Galicia, 2000. doc. 9; Do siquidem vobis pro Causo et pro Belsar et pro Gallegos quantum habeo in Mougales et pro Manuffi duos casales quos habeo in Fornelo pro Nogueira et pro Canedello palatis de Texo et pro Masende do vobis ipsos duos casales quos ibi habeo et alium casalem quod ego habeo in Canedello de Lourima.

${ }^{68}$ Se trata de las localidades de Couso de Limia, Mougás, Mañufe próximas al monasterio Santa María de Oia.

${ }^{69}$ Con anterioridad su padre Fernando Iohannis había tenido la tenencia de este castillo, Carlos Andrés GonzÁlez-PAz, "Una fortaleza medieval en el Camino portugués a Santiago de Compostela: Castellum Sancti Pelagi de Luto", Cuadernos de Estudios Gallegos, LVI, 122, (2009), pág. 157.
} 
y la de la tierra de Lanzada que tuvo entre 1164 y $1165^{70}$. En 1173 aparece por última vez en la documentación haciéndo una donación al monasterio de Santa María de Melón, del que era familiar ${ }^{71}$.

En 1160 posiblemente hubo una nueva ocupación por parte de Alfonso Enríquez, ya que es tenente de Toroño. Sin embargo solo dos años después Fernando II recuperó esta tierra, pues confirma como in temporibus illis reinante rex Fernandus apud Toronio et sub manu eius Pelagius Curvus ${ }^{72}$. No obstante, los enfrentamientos volvieron a estas tierras, pues en 1163 el portugués volvió a invadirlas. En este momento, y para solventar el problema fronterizo, los reyes de León y Portugal establecieron un nuevo acuerdo.

Ambos se reunieron en Lérez, localidad próxima a la frontera, y acordaron el matrimonio entre Fernando II y la infanta portuguesa Urraca Alfonso. Se desconocen muchos aspectos de esta paz, sin embargo es muy elocuente el hecho de que los pocos datos conservados sobre ella procedan de documentación de los nobles de la tierra, implicados en el proceso. El diploma que informa del tempore coadunationis regum scilicet Fernandus rex atque rex Adefonsus Portugalensis, prompti utrumque ad confirmandam ueramque pacem, amicicia inter se et suos, super flumen Lerice in Uetula Ponte ${ }^{73}$, es una donación de Fernando II a Guntadino y su esposa de unos bienes situados en la localidad fronteriza de Fornelos. Confirman el diploma los nobles presentes en la corte leonesa mientras se estaba negociando la paz con Alfonso Enríquez; aunque no se conoce el papel que pudieron desempeñar, suponemos fue importante dadas las implicaciones territoriales. Encabezan la lista de confirmantes Pelayo Curvo y su hermano Varela, Álvaro Rodríguez de Sarria, el hijo de Rodrigo Vela y Pelayo Subredina, seguidos de otros nobles con intereses en la región ${ }^{74}$.

En el acuerdo posiblemente estuvieron involucrados los castillos de Toroño, pues fueron devueltos poco después al rey de León. Asimismo, se pactó el matrimonio entre Fernando II y la hija de Alfonso Enríquez, como señala una donación, efectuada en junio - eo tempore quo rex Fernandus accepit in uxorem filiam regis Portugalensium ${ }^{75}$-, por el rey a Pedro González Arnego, de una heredad situada en la tierra orensana de Cabrera. Ambas donaciones parecen indicar que el leonés estaba reajustando la frontera, condicionada por el acuerdo con Alfonso Enríquez.

\footnotetext{
70 M. Recuero Astray. (dir), Documentos Medievales del Reino de Galicia, Fernando II..., docs. 66, 85.

${ }^{71}$ Pelayo y su esposa establecen un pacto de familiaridad en 1165. Segundo CAmbón, El monasterio de Santa María de Melón, Siglos XII-XIII, vol. I, tesis doctoral inédita, Universidad de Santiago de Compostela, 1957, pág. 115.

72 S. CAmbón, El monasterio de Santa María de Melón ... doc. 24.

${ }_{73}$ M. Recuero Astray (dir.), Documentos Medievales del Reino de Galicia, Fernando II... doc. 69.

${ }^{74}$ Íd. ibid., doc. 69.

75 Íd., doc. 72 .
} 
Pero será un diploma de uno de los nobles presentes en las negociaciones el que informa del límite establecido. Se trata de un documento, datado en julio de 1165, emitido por Pelayo Curvo en cuya data se señala que: Adefonsus regnante a Sancte Axeno usque Vicaulam Pontem. Fernandus rex a Legione usque ad Vetulam pontem ea utraque parte ${ }^{76}$.

No obstante, y a pesar de haber definido la línea divisoria entre los reinos, el monarca portugués volvió a romper la paz casi de inmediato en 1165 . Una pesquisa efectuada por la catedral de Orense informa de que en 1165 Alfonso Enríquez ocupó las tierras de Lorbazana, Cabreira, Baroncelli in tempore guerre regnum, scilicet Fernandi et regis Adephonsi ${ }^{77}$ y que las puso bajo jurisdicción bracarense. Varios testigos afirman que las tuvo usque ad captationem regis portugalensis in Badalouzi $^{78}$, es decir; hasta 1169. Uno de los testigos preguntados indica que las tuvo hasta cuatro meses después del cautiverio del rey en Badajoz ${ }^{79}$.

Alfonso Enríquez había comprendido que su intención de expandir su reino por el norte conllevaría grandes dificultades y por ello intensificó sus acciones en la frontera sur. Sin embargo, su proyecto chocaba con el Tratado de Sahagún en el que Fernando II se había asegurado su zona de expansión que veía amenazada por el ataque portugués a Badajoz en 1169; de modo que el monarca leonés se dirigió a la ciudad para ayudar a las fuerzas musulmanas y logró apresar a su suegro que había caído herido. Tras cuatro meses de cautiverio se pactaron las condiciones de su liberación. No se conocen demasiados detalles pero sí que los castillos de Toroño fueron devueltos a Fernando II $^{80}$, como destacaba el pleito por su jurisdicción entre las sedes de Orense y la Bracarense.

Esta devolución de los castillos llevó consigo un cierto vaivén en la nobleza con intereses en esta región. Así, abandona la corte de Alfonso Enríquez su alférez Pero Pais da Maia. Se trata de un nieto del conde Gómez Nuñez e hijo de Châmoa Gómez quien fuera la concubina de Alfonso Enríquez. Es muy probable que los intereses familiares le llevaran a refugiarse en las tierras de origen de su familia materna, en las que mantenía sus vínculos parentelares, pues su hermana

\footnotetext{
76 S. CAmbón, El monasterio de Santa María de Melón..., doc. 29.

${ }^{77} \mathrm{M}^{\mathrm{a}}$ Beatriz Vaquero Díaz y Francisco Pérez Rodríguez, Colección documental del Archivo de la Catedral de Orense, (888-1230), vol. 1, León, Centro de Estudios e Investigación. S. Isidoro, 2010, doc. 75. (Col. Fuentes y Estudios de Historia Leonesa).

78 Íd. ibid., doc. 74.

79 Íd. ibid., doc. 75. Infra IIII menses post captationem regis Portugalensis venientem ad recipiendam terram de Caprariam et de Lobarzanam.

${ }^{80}$ Artur de Magalhães BASTO, (ed.), Crónica de cinco reis de Portugal, seguida da parte da Crónica Geral de Espanha que insere las histórias dos reis d Portugal, Porto, Livreria, 1960, pág. 109. Narra lo sucedido en 1169 en Badajoz. Tras caer herido, Alfonso Enríquez fue llevado a la tienda de su yerno Fernando II de León que mandó curar sus heridas y cuenta que le diese la tierra de Toronha que se encuentra entre el Miño y el castillo de Lobeira, y además le debía hacer homenaje. Después el leonés lo liberó.
} 
Ximena Pais da Maia había casado con Gonzalo Pelagi de Toroño, hijo de Pelayo Curvo. No tuvo grandes problemas para integrarse en la corte de Fernando II que le entregó la alferecía en 1170, además de varias propiedades en Toroño y la tenencia de Tenzam en 1180 y de Toroño en $1182^{81}$ y en 1184 el rey le donó Guillarey y Sareia en Toroño, aumentando de este modo sus intereses en la zona. Sin embargo, la salida de la corte lusa de Pero Pais da Maia no terminó con los intereses de su familia materna en la corte, pues su medio hermano, el ilegítimo Fernando Alfonso lo sustituyó en la alferecía portuguesa ${ }^{82}$.

Tras la devolución de los castillos de Toroño, Fernando II entregó la tenencia de la tierra al conde Armengol de Urgel, que tenía la mayordomía, además de Limia, Monterroso y la tenencia de la Extremadura. Entregar el gobierno de las tenencias fronterizas a un gran magnate fue una estrategia adoptada por el monarca leonés para blindar las fronteras ante los ataques de los reyes vecinos. Esta política se repetirá en numerosas ocasiones a lo largo de su reinado y en el de su hijo ${ }^{83}$.

1169 representa un hito en el diseño y gobierno de esta región fronteriza. Se llegó a una relación relativamente pacífica en este espacio que sólo se quebraría en el reinado de Alfonso IX. A partir de entonces, los monarcas articularon otros mecanismos para tener controlada la frontera, entre los que destacaban los matrimonios reales y la entrega de las arras de las nuevas reinas en los territorios en litigio.

\section{EL PARENTESCO COMO MEDIO ESTABILIZADOR DE LA FRONTERA.}

\section{LAS ARRAS DE LAS REINAS EN EL CONTROL DE LOS CASTILLOS FRONTERIZOS}

Los matrimonios regios fueron un mecanismo de materialización de alianzas entre reinos, asimismo las dotes y las arras entregadas a las en reinas de León tuvieron un gran valor político, estratégico y territorial en el control del espacio fronterizo ${ }^{84}$. Se desconocen algunos aspectos de las arras entregadas a algunas reinas leonesas, sin embargo entre 1157 y 1230 los reyes de León concedieron a sus esposas en concepto de arras tierras y castillos situados en las tierras de Limia y Toroño, como un elemento para asegurar y pacificar la frontera.

El matrimonio entre la hija de Alfonso Enríquez, Urraca, y Fernando II de León acordado en Lérez en 1165 pretendía poner fin a los enfrentamientos fron-

\footnotetext{
${ }_{81}$ Véase I. Calderón Medina, Cum magnatibus regni mei..., pág. 206-208.

${ }^{82}$ I. Calderón Medina y J. P. Martins Ferreira, "Beyond the border...”, pág. 13.

${ }^{83}$ I. Calderón Medina, Cum magnatibus regni mei..., pág. 208 y ss.

${ }^{84}$ Ana RodRíguez LóPEZ, "Dotes y arras en la política territorial de la monarquía feudal castellana", Arenal: Revista de Historia de las Mujeres, vol. 2, núm. 2 (1995), págs. 271-293. Íd. "Stratégies matrimoniales, stratégies patrimoniales: Autour du pouvoir des femmes au royaume de León-Castille. (IX - XIII ${ }^{\mathrm{e}}$ siècles)", en Martin Aurell, (ed.), Les Stratégies matrimoniales (IX ${ }^{e}$ - XIII ${ }^{e}$ siècles), Turnhout, Brepols, 2013, págs. 169-191.
} 
terizos en las tierras de Limia y Toroño. Aunque no se han conservado noticias de los bienes que fueron entregados en arras a la reina Urraca, todo indica que estuvieron situados en la frontera galaico-portuguesa. Pronto se quebró la paz y los enfrentamientos continuaron hasta 1169 , aunque posteriormente, y mientras duró el matrimonio, no hubo grandes altercados en la frontera.

El segundo enlace de Fernando II fue con Teresa Fernández de Traba, hija ilegítima de Teresa de Portugal y Fernando Pérez de Traba. Con esta alianza el rey de León estaba casándose con una medio-hermana de Alfonso Enríquez, que al tiempo era hija de uno de los más poderosos señores de Galicia y fiel servidor de Fernando II. Tampoco se han conservado referencias a las arras de Teresa, sin embargo durante el tiempo que se mantuvo el matrimonio se consiguió mantener una cierta paz entre los reinos, pues no hay noticias de grandes enfrentamientos en este espacio.

No obstante, las relaciones entre León y Portugal variaron enormemente a lo largo del reinado de Alfonso IX, pasaron de periodos de paz a la invasión leonesa de las tierras norteñas portuguesas. En 1191 los reyes de León, Portugal y Aragón firmaban un acuerdo para frenar el poder de Alfonso VIII de Castilla, que se materializó con el matrimonio entre el leonés y la infanta Teresa, hija de Sancho I. Con esta unión pretendía poner fin a los conflictos territoriales enquistados en las tierras de Toroño y Limia.

No se conocen con exactitud los bienes recibidos en arras por doña Teresa, aunque sí se pueden reconstruir una parte importante ${ }^{85}$. La mayoría de ellos se situaban en las tierras gallegas de Limia y Toroño. Tras la disolución canónica del matrimonio en 1194 y la nueva alianza de Alfonso IX con el rey de Castilla a través del enlace con Berenguela, hubo que solventar varias cuestiones relativas a los castillos de Toroño, que se le habían entregado en arras a Teresa ${ }^{86}$. El tratado de disolución de las arras de doña Teresa de 1194 abrió un proceso que pretendía evitar que esta región terminara en manos del rey de Portugal y que se irá adecuando a las circunstancias políticas vividas en León hasta 1230.

El protagonismo de ciertos nobles en el desarrollo y cumplimiento de este tratado fue destacable. Ambos monarcas eligieron al conde Pedro Fernandes

\footnotetext{
${ }_{85}$ No se ha conservado la carta de arras, pero se hace referencias a ella en varias ocasiones en el tratado de disolución. Es probable que fuera destruida. No obstante, varios diplomas hacen referencia a sus bienes arrales, como el tratado de disolución de las arras, el tratado de Tordehumos y una donación de bienes que Alfonso IX hizo a sus hijas Sancha y Dulce en 1217.

${ }^{86}$ Rui Pinto de Azevedo; Avelino de Jesús da Costa y Marcelino Rodrigues Pereira, Documentos de D. Sancho I (1174-1211), vol. I, Coimbra, Universidad de Coimbra, 1979, doc. 74. Marcelino RodriguES Pereira, "Um desconhecido tratado entre Sancho I de Portugal e Afonso IX de Leão (solução das arras da raihna D. Teresa)", Revista Portuguesa de História, núm. 17 (1978), págs. 105- 131.
} 
de Bragança, como encargado de hacer cumplir las disposiciones del acuerdo ${ }^{87}$. Cada uno de los monarcas puso a su disposición cinco caballeros, todos ellos miembros de familias con intereses en las tierras de Limia y Toroño. Entre los magnates lusos se encontraba, Pedro Alfonso, hijo ilegítimo de Alfonso Enríquez y nieto del conde Gómez Núñez, además de Gonzalo Mendes de Sousa y Gonzalo Gonçalves, y los hermanos Juan y Martín de Riba de Vizela. Mientras, Alfonso IX seleccionó a Ordoño García de Aza, Alfonso Téllez, Rodrigo Pérez de Villalobos, Álvar Díaz de Noreña y Álvaro Peláez. Todos ellos debían permanecer en el castillo de Moreira hasta la resolución del acuerdo ${ }^{88}$.

Alfonso IX, además de entregar tierras por valor de cuatro mil maravedíes a Teresa en la frontera, pondría en manos de Gonzalo Pais, que le había rendido vasallaje, los cuatro castillos de Toroño, cuando quedaran libres de la potestad de Fernando Núñez: los castillos pro pacto regina: Soveroso, Entenza, Tebra y Santa Elena ${ }^{89}$. Si el rey de León no entregaba la tierra acordada a Teresa, Gonzalo daría los castillos, de acuerdo a un orden establecido, que garantizara la tenencia del rey de Portugal. Pero si el monarca lusitano hubiera muerto, los recibiría la infanta y si ésta hubiera casado o fallecido, serían entregados a su hijo el infante Fernando. Si los hijos del matrimonio hubieran muerto, los castillos revertirían al rey de León.

Los monarcas debían entregar cuatro castillos pro pace a los maestres de las órdenes militares. Posteriormente, se acordaba la devolución por parte de Sancho I de Cabritam, Asperello y Toroño y los otros castillos de las arras de Limia. Además el portugués establecía que Alfonso IX no debía aumentar las defensas del castillo de Cabrera, que era una pieza clave para la defensa de la frontera en la tierra orensana ${ }^{90}$.

Cuando Alfonso IX acordó su matrimonio con Berenguela de Castilla, tierras y castillos situados en Limia y Toroño volvieron a ser parte integrante de las arras entregadas a su nueva esposa. A pesar de que el acuerdo estaba encaminado a solventar el problema fronterizo entre León y Castilla, ciertos castillos de la frontera galaico-portuguesa fueron concedidos a la reina. La infanta castellana recibió los castillos de Sanctum Pelagium de Lodo, Aguilar de Mola, Alba de Bunel, Candrei, Aguilar de Pedraio ${ }^{91}$, que estaban bajo la tenencia de Pelayo Subredina, que había participado en la paz de Lérez. De nuevo se articuló un

\footnotetext{
${ }_{87}$ En trabajos anteriores cometimos un error de identificación del conde Pedro, al que consideramos como Pedro Fernández de Castro, no obstante éste no tuvo dignidad condal, por lo que se trataría de Pedro Fernandes de Bragança. I. CALdERÓn MedinA, "Las arras de la reina Teresa...”, págs. 443- 455.

${ }_{88}$ Íd. ibid., doc. 1.

${ }^{89}$ I. CAlderón Medina, "Las arras de la reina Teresa..." págs. 443- 444.

${ }^{90}$ M. Pereira, Un desconhecido tratado..., págs. 128-129.

91 Julio GonzÁLeZ, Regesta de Fernando II, Madrid, Instituto Jerónimo Zurita, 1943, doc. 135.
} 
complejo sistema de garantía que regulaba la posesión de estas fortalezas: quien rompiera el pacto perdería los castillos, si Berenguela era abandonada o muerta por orden rey de León, éste perdería las fortalezas que serían entregadas al rey de Castilla. Pero si la reina moría antes que el rey sin haber engendrado hijos legítimos, los castillos revertirían a Alfonso IX; si no, serían los hijos legítimos quienes los heredaran. No obstante si el rey de León fallecía antes de la reina, los castillos serían entregados a Berenguela ${ }^{92}$.

Tras la anulación del matrimonio de la infanta castellana y el monarca leonés, los castillos de las arras situados en Toroño fueron objeto de nuevas negociaciones. Todos ellos, a excepción de Candrei, fueron entregados a su hijo Fernando por las disposiciones del tratado de Cabreros de 1206. En este tratado el leonés entregaba a sus hijas Sancha y Dulce los castillos que habían pertenecido a las arras de su madre: Enteza, Soveroso, Santa Helena y Tevira ${ }^{93}$.

En 1211 las relaciones con Portugal se tensaron tras la muerte de Sancho I y la llegada al trono de Alfonso II que se enfrentó con sus hermanas ${ }^{94}$. En ese momento, Alfonso IX entregó la tenencia de los castillos de Toroño a Juan Fernández de Limia y posteriormente la tendría Martín Sanches, ilegítimo de Sancho I de Portugal y María Aires de Fornelos ${ }^{95}$.

En 1214 moría el infante Fernando, lo que desbarataba el sistema de garantías del acuerdo de disolución de las arras de Teresa de 1194. Para evitar que los castillos cayeran en manos del rey de Portugal, Alfonso IX en 1217 donó numerosos bienes a sus hijas Sancha y Dulce, entre los que destacaban los castillos Entenza, Soveroso, Tebra y Santa Helena, que debían tenerlos durante toda su vida; pero tras su muerte, serían entregados a quien ocupara el trono de León ${ }^{96}$. Asimismo, concedía a las infantas otros muchos castillos y tierras de frontera como Cabrera de Baronceli, Lobarzana, Candrei, Portela de San Juan, Ribera, Celme, Asperelo, Araujo, Santa Cruz, Burgo de Ribadavia, San Juan de la Barra, Allariz, Mimalda y todo cuanto le pertenecía en Limia, a excepción de Aguilar de Moa y Aguilar de Pedrario, que formaban parte de a las arras de Berenguela ${ }^{97}$.

\footnotetext{
92 A. Rodriguez López, “Dotes y arras...”, págs. 290-293.

93 José María Fernández Catón, Colección documental del Archivo de la Catedral de León, VI. (11881230), vol. 46, León, 1991, doc. 1786 (Col. Fuentes y Estudios de Historia Leonesa).

${ }^{94} \mathrm{M}^{\mathrm{a}}$ Teresa Veloso, "A questão entre Afonso II e suas irmãs sobre a detenção dos direitos senhoriais", Revista Portuguesa de História, 18 (1980), págs. 197-229.

95 I. Calderón Medina, Cum magnatibus ..., pág. 323. Julio GonzÁlez, Alfonso IX, vol. 2, Madrid, CSICInstituto Jerónimo Zurita, 1944, doc. 275.

96 Preterea concedo et confirmo quod si mater earum regina donna Theresa premortua eis fuerit, castra que ipsa tenet, scilicet, Entenza, Soveroso, Sanctaenia et Tevura ad eas devolvantur in tota vita sua sine contradictione qualibet possidenda, eo modo quo de aliis castris supradictum est. J. GonZÁLEZ, Alfonso IX..., doc. 342 .

${ }^{9}$ Íd. ibid., doc. 342 .
} 
Con estas disposiciones el rey estaba asegurando la posesión de esta franja fronteriza en manos de la monarquía leonesa, en un tiempo en el que los enfrentamientos bélicos con Alfonso II de Portugal alcanzaron altas cotas de violencia en la década de los años veinte. Sin embargo, en 1230 y ante las dificultades de controlar el reino de León las infantas Sancha y Dulce renunciaron a sus derechos y entregaron a Fernando III todas sus propiedades entre las que se encontraban los castillos de Limia y Toroño.

\section{Conclusiones}

En las páginas anteriores se han analizado dos estrategias desarrolladas por la monarquía para el trazado y el control de la frontera galaico-portuguesa. Los reyes trataron de atraer la fidelidad de la nobleza local además de establecer matrimonios regios con el fin de terminar con los enfrentamientos. Las alianzas matrimoniales conllevaban la entrega a las reinas de los castillos y tierras limítrofes para que aseguraran la frontera.

La solidez de los vínculos familiares y patrimoniales que la nobleza gallega había tejido no se deshicieron con la creación de la nueva frontera, por ello los nobles tuvieron que reajustar sus relaciones con las dos monarquías enfrentadas, que, a su vez, dependían del apoyo nobiliario para definir su reino.

Las fuentes muestran el protagonismo de la nobleza en el trazado y control de la frontera. Destacan la importancia de mantener la fidelidad de los señores locales y las consecuencias de perderla, como en los casos del conde Gómez Núñez de Celanova/ Pombeiro y Rodrigo Fernández Veloso, a quienes acusan de la pérdida de territorio por parte de Alfonso VII. Al mismo tiempo, elogian la fidelidad de Fernando Iohannes de Montor-Toroño y sus hijos Pelayo Curvo y Varela, en la defensa, lo que les granjeó el aumento del poder en la corte leonesa.

Asimismo las fuentes dejan ver la relevancia de la nobleza local en la guerra: algunos son considerados los instigadores, otros muchos fueron hechos prisioneros, aunque no se conocen con exactitud ni sus nombres ni las consecuencias del cautiverio; otros, sufrieron pérdidas en el reino vecino que fueron suplidas por donaciones del rey al que habían permanecido fiel.

La Chronica Adephonsi Imperatoris y los Annales del rey de Portugal presentan a los magnates locales como impulsores de las negociaciones y la firma de la paz. Pero también los acuerdos de las arras entregadas a las reinas leonesas implicaron a los señores de frontera, puesto que los castillos se encontraban en las tierras que les pertenecían. Muchos de ellos tuvieron destacados papeles en el establecimiento y cumplimiento de los pactos, pues actuaron como árbitros y garantes de los tratados que regulaban las arras de las reinas. Se diría que es una empresa conjunta con la monarquía ya que el trazado de las fronteras afectaba directamente a sus tierras y, por lo tanto, tuvieron un alto grado de participación. 


\section{BIBLIOGRAFÍA}

Andrade, Amélia Aguiar, Vilas, poder régio e frontera: O exemplo do entre Lima e Minho medieval, Lisboa, Universidade Nova de Lisboa, 1994.

Azevedo, Rui Pinto de (ed.), Documentos Medievais Portugueses, Documentos Régios, (DMP. DR.), vol. 1, Tomo I, Lisboa, Academia Portuguesa da História, 1961.

Azevedo, Rui Pinto de; Costa, Avelino de Jesús da y Pereira, Marcelino Rodrigues, Documentos de D. Sancho I (1174-1211), vol I, Coimbra, Universidad de Coimbra, 1979.

Basto, Artur de Magalhães (ed.), Crónica de cinco reis de Portugal, seguida da parte da Crónica Geral de Espanha que insere las histórias dos reis d Portugal, Porto, Livreria, 1960.

Blöker-Walter, Monica, Alfons I von Portugal. Studien zu Geschichte und Sage des Begrunders der portugiesichen Unbhangigkeiten, Zurich, Fretz und Wasmuth Verlag, 1966.

Calderón Medina, Inés y Ferreira, João Paulo Martins, "Beyond the border. The aristocratic mobility between the kingdoms of Portugal and León (1157-1230)", E-journal of Portughese History, vol 12, núm.1 (2014), disponible en <http://www.brown.edu/Departments/ Portuguese_Brazilian_Studies/ejph/html/issue23/pdf/v12n1a01.pdf $>$ [Consulta 4/03/2017].

Calderón Medina, Inés, "El concubinato regio en la definición de la frontera galaico-portuguesa (s. XII-XIII)" [en prensa].

Calderón Medina, Inés, "La solidaridad familiar. La participación de la nobleza leonesa en la guerra civil portuguesa (1245-1247)”, Hispania, vol. 73, núm. 245 (2013), págs. 617-645.

Calderón Medina, Inés, "El panorama político de la península ibérica en 1200 (ca.1150-1230)" en López Ojeda, Esther (coord.), en XIII Semana de estudios medievales de Nájera: 1212, un año, un reinado, un tiempo de despegue, Logroño, Instituto de Estudios Riojanos, 2013, págs. 103-138.

Calderón Medina, Inés, "Las arras de la reina Teresa, el tratado entre Sancho I de Portugal y Alfonso IX de León", en Isabel Val Valdivielso y Pascual Martínez Sopena, Castilla y la sociedad feudal. Homenaje al profesor D. Julio Valdeón Baruque, vol. II, Valladolid, Junta Castilla y León, 2009, págs. 443- 455.

Calderón Medina, Inés, Cum magnatibus regni mei. La nobleza leonesa y el poder regio durante los reinados de Fernando II y Alfonso IX de León (1157-1230), núm. 74, Madrid, CSIC, 2011 (Col. Biblioteca de Historia).

Cambón, Segundo, El monasterio de Santa María de Melón, Siglos XII-XIII, vol. I, tesis doctoral inédita, Santiago de Compostela, Universidad de Santiago de Compostela, 1957.

Cardim, Pedro; Fonseca, Luis Adão da y González Paz, Carlos Andrés, "A fronteira e a estruturação do espaço", en Fonseca, Luis Adão da (coord.), Entre Portugal e a Galiza. (secs. XI A XVII).Un olhar peninsular sobre uma região histórica, Porto, CEPESE-Fronteira do Caos Editores, 2014, págs. 225-253.

Falque Rey, Emma, Historia Compostelana, Madrid, Akal, 1994.

Fernández Catón, José María, Colección documental del Archivo de la Catedral de León, VI. (1188-1230), León, Centro de Investigaciones y Estudio San Isidoro, 1991, (Col. Fuentes y Estudios de Historia Leonesa, 46).

Fernández Flores, José Antonio, Colección diplomática del monasterio de Sahagún, (857-1300), León, Centro de Estudios e Investigación San Isidoro, 1991 (Col. Fuentes y Estudios de Historia Leonesa, 38). 
Fernández Rodríguez, Manuel, Toronium: aproximación a la historia de una tierra medieval, Santiago de Compostela, CSIC, 2004 (Anejos de Cuadernos de Estudios Gallegos, 31).

Ferreira, María do Rosario, "O reino de Portugal na Chronica Adephonsi Imperatoris", e-Spania, 15 (2013), disponible en $<$ http://e-spania.revues.org/22317?lang=es $>$ [Consulta 5/03/2017].

Ferreira, João Paulo Martins, A Nobreza Galego-Portuguesa da Diocese de Tui (915-1381), tesis doctoral inédita, Porto, Universidade do Porto, 2016.

González, Julio, Alfonso IX, vol. 2, Madrid, Instituto Jerónimo Zurita, 1944.

González, Julio, Regesta de Fernando II, Madrid, Instituto Jerónimo Zurita, 1943.

Gouveia, Mário de, "Nuno Mendes (?-1071): o ultimo conde de Portucale", Revista Portuguesa de História, núm. 44 (2013), págs. 153-187.

González-Paz, Carlos Andrés, "Una fortaleza medieval en el Camino portugués a Santiago de Compostela: Castellum Sancti Pelagi de Luto", Cuadernos de Estudios Gallegos, LVI, 122, (2009), págs. 151-170.

Iglesias Almeida, Ernesto, O antigo bispado de Tui en Portugal, Noia, Toxosoutos, 2007.

López Sangil, José Luis, A nobreza altomedieval galega. A familia Froilaz-Traba, Noia, Toxosoutos, 2005.

Marques, André, Da representação documental à materialidade do espaço. Território da diocese de Braga (séculos IX-XI), Porto, CITCEM, Centro de Investigação Transdisciplinar, Cultura, Espaço e Memória; Afrontamento, 2014.

Marques, José, “A fronteira do Minho, espaço de convivência galaico-minhota, na Idade Média” en F. Ribeiro da Silva et. al. (coord.), Estudos em homenagem a Luís António de Oliveira Ramos, Porto, Faculdade de Letras da Universidade do Porto, 2004, vol 2, págs. 697- 712.

Marques, José, Relações entre Portugal e Castela nos finais da Idade Média, Lisboa, Fundação Calouste Gulbenkian, 1994.

Mattoso, José, “A nobreza portuguesa con contexto peninsular”, IV Jornadas Luso-espanholas de História Medieval. As relações de fronteira no século de Alcañices. Revista da Faculdade de Letras. História, II serie, vol. XV, tomo II (1998), págs, 1019-1044.

Mattoso, José, “A primeira tarde portuguesa”, Portugal medieval, Lisboa, Novas interpretações: Imprensa Nacional/Casa da Moeda, 1985, págs. 11-35.

Mattoso, José, Afonso Henriques, Lisboa, Circulo de Leitores, 2006 (Col. Reis de Portugal).

Maya Sánchez, Antonio (ed.), “Chronica Adephonsi imperatoris”, en Falque, Gil, Maya Sánchez (eds.), Chronica Hispana saeculi XII, Turnhout, Brepols, 1991 (Corpus chistianorum. Continuatio medievalis, 71).

Pereira, Marcelino, "Um desconhecido tratado entre Sancho I de Portugal e Afonso IX de Leão (solução das arras da raihna D. Teresa)”, Revista Portuguesa de História, 17 (1978), págs. 105- 131.

Pizarro, José Augusto Sottomayor, As linhagens medievais portuguesas: genealogías e estratégias, (1279-1325), Porto, Centro de Estudos de Genealogia, Heráldica e História da Família, Universidade Moderna, 1999.

Pizarro, José Augusto Sottomayor, “O nascimento de Portugal. Uma perspetiva nobiliárquica (1096-1157/1300)", Revista Portuguesa de Història, núm. 44 (2013), págs. 29-58.

Portela, Ermelindo, García II de Galicia, el rey y el reino (1065-1090), Burgos, La Olmeda, 2001. 
Portela, Ermelindo, La región del obispado de Tuy en los siglos XII al XV: Una sociedad en la expansión y en la crisis, Santiago de Compostela, Universidad de Santiago de Compostela, 1976.

Recuero Astray, Manuel (dir.), Romero Portilla, Paz y Rodríguez Prieto, Ángeles, Documentos Medievales del Reino de Galicia, Fernando II (1155-1188), La Coruña, Xunta de Galicia, 2000.

Recuero Astray, Manuel, González Vázquez, Marta y Romero Portilla, Paz, Documentos Medievales del Reino de Galicia: Alfonso VII (1116-1157), La Coruña, Xunta de Galicia, 1998.

Reglero de la Fuente, Carlos Manuel, "Visión y construcción del espacio en la Chronica Adephonsi Imperatoris", e-Spania, 15 (2013), disponible en <http://e-spania.revues. org/22367> [Consulta 5/03/2017].

Rodríguez López, Ana, "Dotes y arras en la política territorial de la monarquía feudal castellana", Arenal. Revista de Historia de las Mujeres, vol. 2, nº 2 (1995), págs. 271-293.

Rodríguez López, Ana, "Stratégies matrimoniales, stratégies patrimoniales: Autour du pouvoir des femmes au royaume de León-Castille. (IXe- XIIIe siècles)", en Martin Aurell (ed.), Les Stratégies matrimoniales (IXe-XIIIe siècles), Turnhout, Brepols, 2013, págs. 169-191.

Romero Portilla, Paz, "Un observatorio privilegiado de las relaciones de Portugal y Castilla: Tuy en la Edad Media", en Estudos em homenagem ao profesor doutor José Marques, vol. IV, Porto, Faculdade de Letras da Universidade do Porto, 2006, págs. 247-259.

Souto Cabo, José Antonio, "Fernando Pais de Tamalhancos. Trovador e Cavaleiro", Revista de Literatura medieval, núm. 24 (2012), págs. 231-267.

Torres Sevilla, Margarita, "Relaciones fronterizas entre León y Portugal en tiempos de Alfonso VII. El ejemplo de la casa de Traba", Revista da Faculdade de Letras. História, núm. 15, vol. I (1998), págs. 301-312.

Vaquero Díaz, Ma Beatriz y Pérez Rodríguez, Francisco, Colección documental del Archivo de la Catedral de Orense, (888-1230), vol. 1, León, Centro de Estudios e Investigación. S. Isidoro, 2010 (Col. Fuentes y Estudios de Historia Leonesa, 131).

Veloso, Ma Teresa, "A questão entre Afonso II e suas irmãs sobre a detenção dos direitos senhoriais”, Revista Portuguesa de História, 18 (1980), págs. 197-229.

Vital Fernández, Sonia, "La participación política de la nobleza gallega en el reinado de Alfonso VII (1126-1157)”, Studia Historica, Historia Medieval, núm. 29 (2011), págs. 99-120. 
